\title{
CONF-960569--24 GA-A22347
}

RECEIYEO

\section{COMPREHENSIVE 2D MEASUREMENTS OF RADIATIVE DIVERTOR PLASMAS IN DIII-D}

JUL 30 1997?

OSTL

by

M.E. Fenstermacher, R.D. Wood, S.L. Allen, N.H. Brooks, D.A. Buchenauer,

T.N. Carlstrom, J.W. Cuthbertson, E.J. Doyle, T.E. Evans, P.-M. Garbet,

R.W. Harvey, D.N. Hill, A.W. Hyatt, R.C. Isler, G. Jackson, R.A. James, R. Jong, C.C. Klepper, C.J. Lasnier, A.W. Leonard, M.A. Mahdavi, R. Maingi, W.H. Meyer, R.A. Moyer, D.G. Nilson, T.W. Petrie, G.D. Porter, T.L. Rhodes, M.J. Schaffer, R.D. Stambaugh, D.M. Thomas, S. Tugarinov, M.R. Wade, J.G. Watkins, W.P. West, and D.G. Whytej
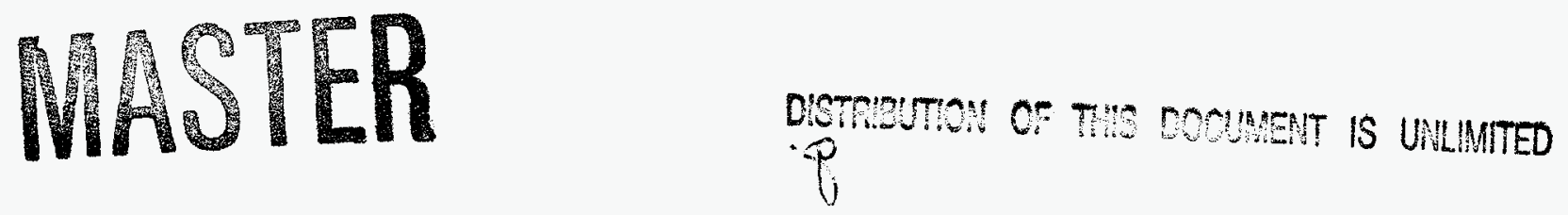

JULY 1997 
This report was prepared as an account of work sponsored by an agency of the United States Government. Neither the United States Government nor any agency thereof, nor any of their employees, makes any warranty, express or implied, or assumes any legal liability or responsibility for the accuracy, completeness, or usefulness of any information, apparatus, product, or process disclosed, or represents that its use would not infringe upon privately owned rights. Reference herein to any specific commercial product, process, or service by trade name, trademark, manufacturer, or otherwise, does not necessarily constitute or imply its endorsement, recommendation, or favoring by the United States Government or any agency thereof. The views and opinions of authors expressed herein do not necessarily state or reflect those of the United States Government or any agency thereof. 


\section{DISCLAIMIER}

Portions of this docament may be illegible in electronic image products. Images are produced from the best available original docoment. 


\title{
COMPREHENSIVE 2D MEASUREMENTS OF RADIATIVE DIVERTOR PLASMAS IN DIII-D
}

\author{
by
}

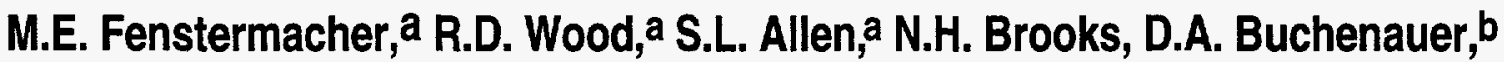

T.N. Carlstrom, J.W. Cuthbertson, C E.J. Doyle, d T.E. Evans, P.-M. Garbet,e

R.W. Harvey, D.N. Hill, a A.W. Hyatt, R.C. Isler, ${ }^{f}$ G. Jackson, R.A. James, ${ }^{a}$ R. Jong, a C.C. Klepper, ${ }^{f}$ C.J. Lasnier, ${ }^{a}$ A.W. Leonard, M.A. Mahdavi, R. Maingi,g W.H. Meyer, ${ }^{a}$

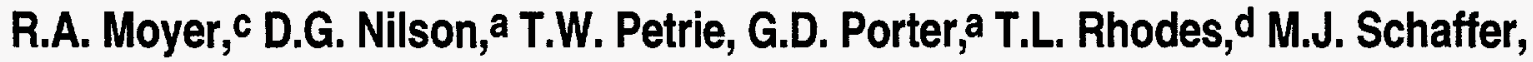

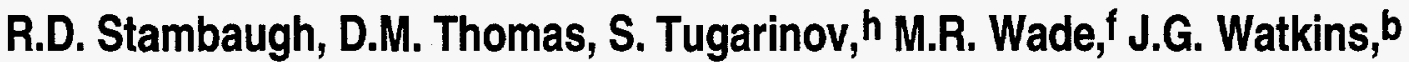
W.P. West, and D.G. Whytel

This is a preprint of a paper to be presented at the 12th International Conference on Plasma Surface Interactions on Controlled Fusion Devices, May 20-24, 1996, Saint-Raphael, France and to be published in the Proceedings.

a Lawrence Livermore National Laboratory, Livermore, California

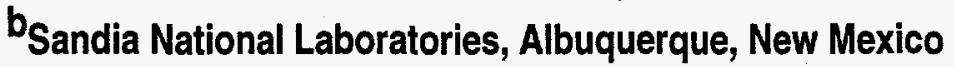

CUniversity of California, San Diego, California

dUniversity of California, Los Angeles, California

eAssociation EURATOM-CEA sur la fusion, Cadarache, France

fOak Ridge National Laboratory, Oak Ridge, Tennessee

GTRINITI, Troitsk, Russia

IINRS-Energie et Materiaux, Varennes, Quebec, Canada

Work supported by

the U.S. Department of Energy

under Contract Nos. DE-AC03-89ER51114, W-7405-ENG-48, DE-AC04-94AL85000, DE-AC05-96OR22464, and Grant Nos. DE-FG03-86ER53266 and DE-FG03-95ER54294

\section{GA PROJECT 3466 JULY 1997}




\begin{abstract}
This paper presents a comparison of the total radiated power profile and impurity line emission distributions in the SOL and divertor of DIII-D. This is done for ELMing H-mode plasmas with heavy deuterium injection (Partially Detached Divertor operation, PDD) and those without deuterium puffing. Results are described from a series of dedicated experiments performed on DIII-D to systematically measure the 2-D $(R, Z)$ structure of the divertor plasma. The discharges were designed to optimize measurements with new divertor diagnostics including a divertor Thomson scattering system. Discharge sequences were designed to produce optimized data sets against which SOL and divertor theories and simulation codes could be benchmarked. During PDD operation the regions of significant radiated power shift from the inner divertor leg and SOL to the outer leg and $\mathrm{X}$-point regions. $D_{\alpha}$ emission shifts from the inner strikepoint to the outer strikepoint. Carbon emissions (visible CII and CIII) shift from the inner SOL near the $\mathrm{X}$-point to a distributed region from the $X$-point to partially down the outer leg during moderate $\mathrm{D}_{2}$ puffing. In heavy puffing discharges the carbon emission coalesces on the outer separatrix near the $\mathrm{X}$-point and for very heavy puffing it appears inside the last closed flux surface above the $\mathrm{X}$-point. Calibrated spectroscopic measurements indicate that hydrogenic and carbon radiation can account for all of the radiated power. $\mathrm{L}_{\alpha}$ and CIV radiation are comparable and when combined account for as much as $90 \%$ of the total radiated power along chords viewing the significant radiating regions of the outer leg.
\end{abstract}




\section{INTRODUCTION}

Finding a method to lower the high target plate heat flux predicted to occur in future tokamak divertor scenarios continues to be one of the important research areas on tokamaks worldwide. A promising solution is to increase the radiation in the divertor legs thereby reducing the heat flux to the target plates and spreading the exhaust power over a large area in the divertor. Experiments in DIII-D have demonstrated such an increase in radiation and corresponding decrease in target plate peak and integrated heat flux by injection of deuteruim gas during the discharge [1]. Detailed studies of the divertor plasma in these discharges [2] have shown that the density, temperature and pressure are lower near the separatrix after the transition to higher radiation, but remain high further out in the SOL. This operating mode has been referred to as the Partially Detached Divertor (PDD) since the detachment behavior is primarily near the separatrix and the plasma remains essentially attached in the outer SOL. Radiation profiles [3] during PDD operation show a shift to the outboard leg and X-point region compared with standard ELMing $\mathrm{H}$-mode without deuterium injection.

This paper will concentrate on comparisons between the profiles of total divertor radiation and measured profiles of visible and EUV emission from hydrogen and impurity species in the divertor plasma. Use will be made of data from multiple overlapping divertor diagnostics. The data were obtained during experiments which were optimized for 2-D measurements of the divertor plasma. Similar work, with limited chordal views, was done for ohmic (limited and diverted) and neutral beam heated (L-mode, diverted) plasmas in JT60-U by Kubo [4]. Work of this kind has also been done in Alcator C-Mod [5]. The focus here will be to compare multiple diagnostics measuring line radiation with different views of the divertor to construct 2-D profiles of the constituents of the total radiation measured by a 2-D bolometer system. 


\section{OVERVIEW OF DIVERTOR CHARACTERIZATION EXPERIMENTS}

In a recent experimental campaign we have systematically measured the $2-D(R, Z)$ structure of the divertor plasma from the inner strikepoint (ISP) to outside the outer strikepoint (OSP) and from the target plates to above the $\mathrm{X}$-point. All discharges in this campaign were lower single null plasmas. Parameters were in the following ranges: $I_{p}=0.9$ to 1.5 MA, $\mathrm{B}_{\mathrm{t}}=2.1 \mathrm{~T}, \mathrm{P}_{\mathrm{inj}}=1$ to $10 \mathrm{MW}$, and $q_{95}=3.7$ to 6.6 . The nominal plasma had the $\nabla \mathbf{B}$ drift toward the divertor although approximately 30 discharges were done with reversed toroidal field. Many of the discharges were repeated several times with divertor spectrometers tuned to different spectral regions to obtain data on many radiating charge states for a given plasma condition.

Radial sweeps of the divertor plasma were used to allow diagnostics with vertical views (in particular the new divertor Thomson system) to sample the entire divertor plasma. The nominal equilibrium had the $X$-point height above the vessel floor, $Z_{X}=15 \mathrm{~cm}$, elongation, $\kappa=1.7$ to 1.9 and triangularity, $\delta=0.3$ to 0.55 (large variation during the sweep). During most of the discharges, the divertor strikepoints were swept radially by as much as $25 \mathrm{~cm}$, the $\mathrm{X}$-point moved as much as $18 \mathrm{~cm}$ while the shape and position of the core plasma and upper SOL were held constant. Divertor cryopumping was not done in this campaign because it requires proximity of the OSP to the entrance of the pumping region. For this work it is assumed that conditions in the divertor remained nearly constant as the plasma is moved since the configuration is essentially an open divertor on horizontal targets without pumping throughout the sweep.

The dataset generated from this campaign includes core $n_{e}, T_{e}$ and $T_{i}$, from Thomson scattering and CER systems respectively, and divertor $n_{e}, T_{e}$ from a new Thomson scattering system viewing the divertor from below [6]. Radiated power is determined in 2-D by tomographic reconstruction of data from a 48-channel bolometer system with crossed views, recycling fluxes are obtained from absolutely calibrated photodiodes, and target plate heat and particle fluxes are measured by IRTV and Langmuir probes respectively. Data on impurity behavior is obtained from images of visible emission lines using tangentially and vertically viewing video cameras, chordal views by multiple visible spectrometers, and absolutely calibrated UV spectrographs with $1 \AA$ resolution in the core and divertor.

Experiments were done with plasmas in ohmic (O), L-mode (L), ELMing H-mode $(\mathrm{H})$, and Reversed $B_{t}$ operation ( $\nabla B$ drift away from the $\mathrm{X}$-point). In addition, radiative divertor plasmas with a Partially Detached Divertor (PDD) induced by $\mathrm{D}_{2}$ injection and with Enhanced Radiation induced by Impurity (ERI) injection (neon and nitrogen) were studied. This paper will focus on comparisons of ELMing H-mode plasmas with and without a PDD condition; results from the other operating modes will be given elsewhere [7-9]. 


\section{COMPARISON OF RADIATION AND IMPURITY DISTRIBUTIONS DURING PDD}

Data from five different systems (bolometers, tangentially and vertically viewing video system images (TTV and VTV), divertor visible and EUV SPRED spectrometers) have been used to develop a comparison between the total radiated power profile and a 2-D spatial distribution of hydrogenic and carbon impurity species. Multiple discharges, all with $\mathrm{I}_{\mathrm{p}}=$ 1.4 MA, $\mathrm{B}_{\mathrm{t}}=2.1 \mathrm{~T}, \mathrm{P}_{\mathrm{inj}}=4 \mathrm{MW}$, and $q_{95}=4.3$, have been used to develop this comparison. The temporal evolution of various signals from one of the discharges is shown in Fig. 1. Gas is injected at $2.8 \mathrm{~s}$ and the transition to the PDD occurs within $100 \mathrm{~ms}$.

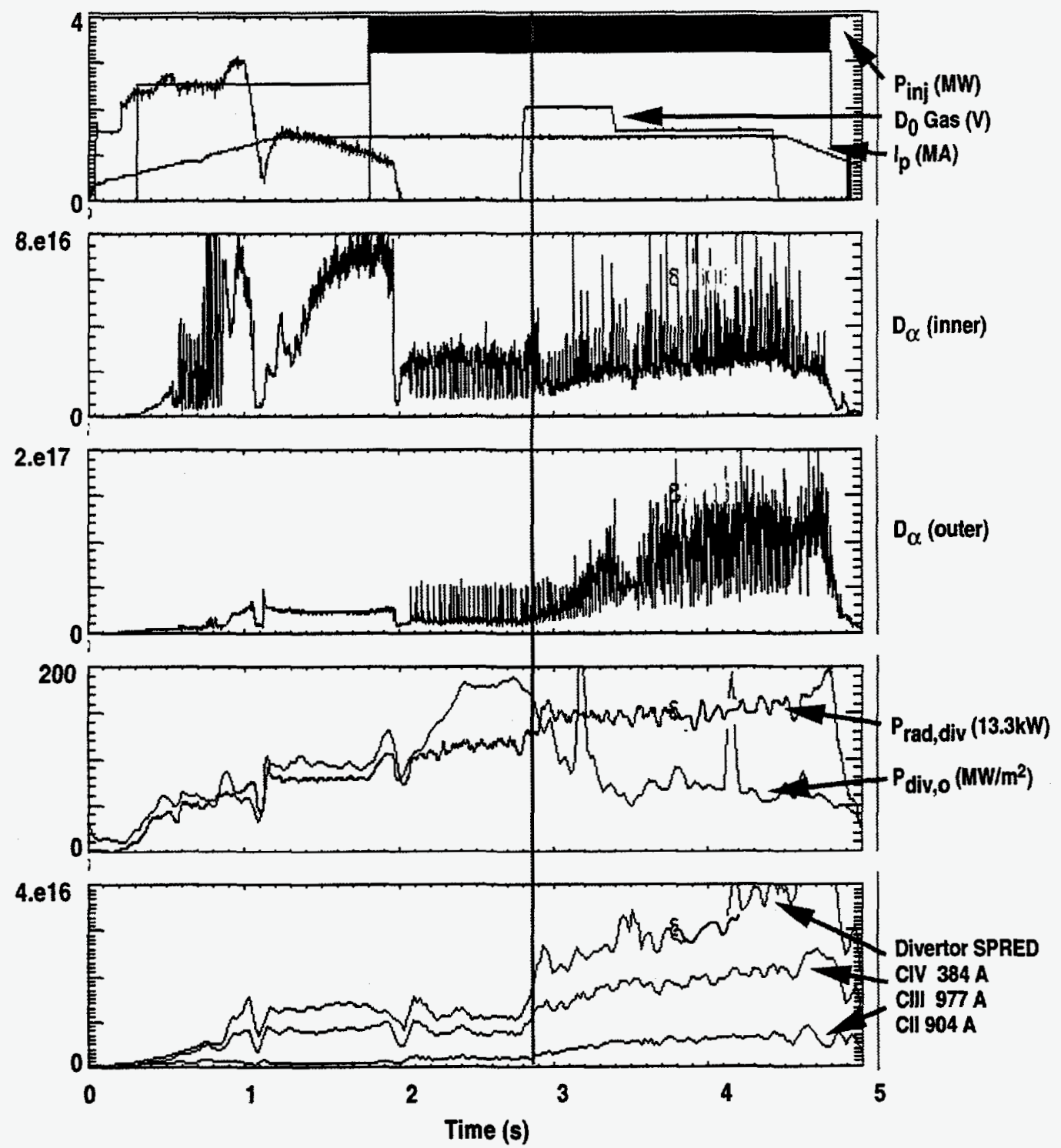

Fig. 1. Temporal evolution of discharge 87506 showing (a) Plasma current, beam power and deuterium injection, (b) inner leg $\mathrm{D}_{\alpha}$ monitor, (c) outer leg $\mathrm{D}_{\alpha}$ monitor, (d) outer target plate peak heat flux and divertor radiated power, (e) divertor brightness of CII, CIII and CIV lines. Evidence of a transition to PDD operation occurs within $100 \mathrm{~ms}$ after deuterium injection at $2800 \mathrm{~ms}$. 
Poloidal profiles of radiated power are obtained from tomographic reconstructions using the crossed bolometer chords. Similar techniques are used to construct 2-D images of line emission from the 3-D TTV data assuming toroidal symmetry. Spatial calibration of the TTV data is verified by comparing with other diagnostics having different views [10]. The VTV provides well calibrated radial emission profiles. The vertical location of radiating zones is obtained by combining radiating zone temperatures, inferred from line ratios using the divertor SPRED data, and $\mathrm{T}_{\mathrm{e}}$ from divertor Thomson scattering. Qualitative consistency has been obtained among all of these measurements for ELMing $\mathrm{H}$-mode plasmas without deuterium injection and for PDD operation.

Typical reconstructions of total radiated power from the bolometer arrays are shown in Fig. 2 at times before and during the PDD operation. Prior to the transition to the PDD mode, the maximum radiated power density occurs in the inner leg leading to low target heat flux there. In PDD operation the radiated power density increases throughout the divertor. The peak shifts to the outer leg and $\mathrm{X}$-point regions, and the peak outer heat flux drops a factor of 3-5 (see Fig. 2).

Fig. 3(a) shows the temporal behavior of the power radiated by hydrogen and by several charge states of carbon and Fig. 3(b) shows the inferred vertical location of the radiation calculated by combining divertor SPRED and Thomson scattering data. The SPRED data indicates that CIV lines below the bandpass of the visible cameras are the major radiators, in agreement with Kubo [4]. Hydrogenic radiation can be comparable to CIV when the line of sight is near the OSP. The SPRED analysis of the effective temperature in the radiating zone for different carbon charge states is obtained from line ratios. It indicates that CIV radiates at approximately $9-11 \mathrm{eV}$ and $\mathrm{CIII}$ radiates at $6-8 \mathrm{eV}$. The vertical locations of the radiating zones of these charge states are within $1 \mathrm{~cm}$ of each other throughout the discharge.

Reconstructions of $\mathrm{D}_{\alpha}$ and CIII visible line emission (656.3, and $465.0 \mathrm{~nm}$ respectively) from the TTV during the ELMing H-mode and PDD phases are shown in Figs. 4 and 5 respectively. During ELMing $\mathrm{H}$-mode the location of the peak in the bolometer power corresponds to the measured $\mathrm{D}_{\alpha}$ visible line emission. The visible emission from CIII (a good indicator of the location of the major radiator, CIV [see Fig. 3]) appears in both divertor legs and along the inner SOL. The inner SOL and ISP emission are consistent with radiation observed on the bolometers. The outer leg emission near the OSP is not observed in the bolometer reconstruction for this discharge timeslice, but it may not be visible by the lower bolometer array in this equilibrium. In ELMing $\mathrm{H}$-mode discharges with equilibria in which the OSP is visible by the horizontal bolometer channels, the local peak in bolometer radiation in the outer divertor occurs near the OSP. During PDD operation, the total radiated power shifts to the outer leg and $\mathrm{X}$-point regions. The visible emission data indicates that the radiation from the $\mathrm{X}$-point region is primarily from carbon. Hydrogen radiation accounts for 


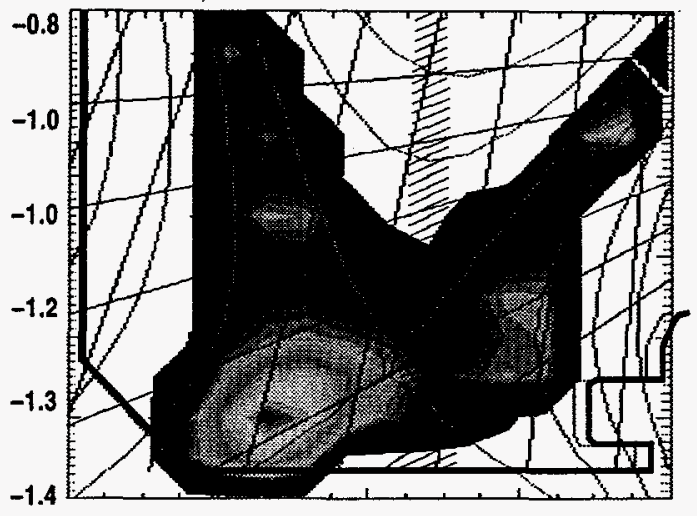

(a)
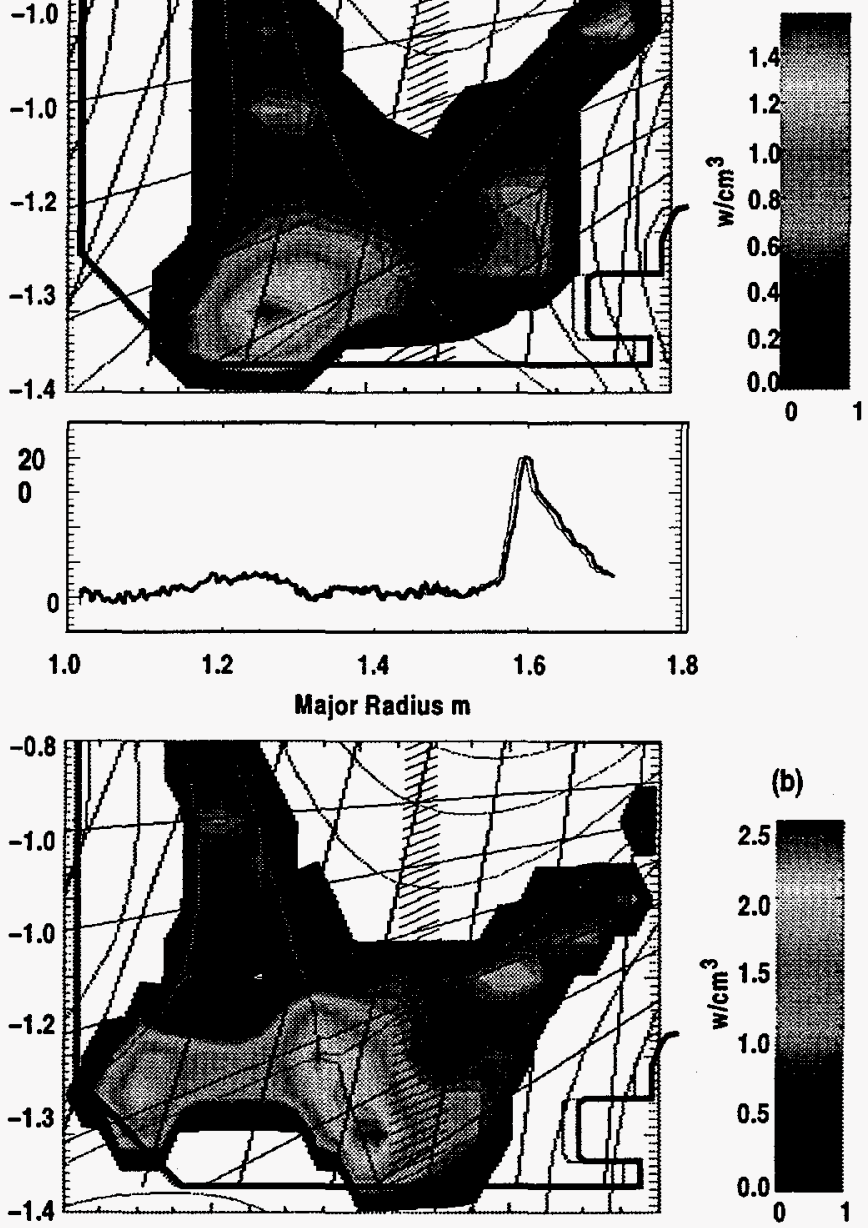

(b)
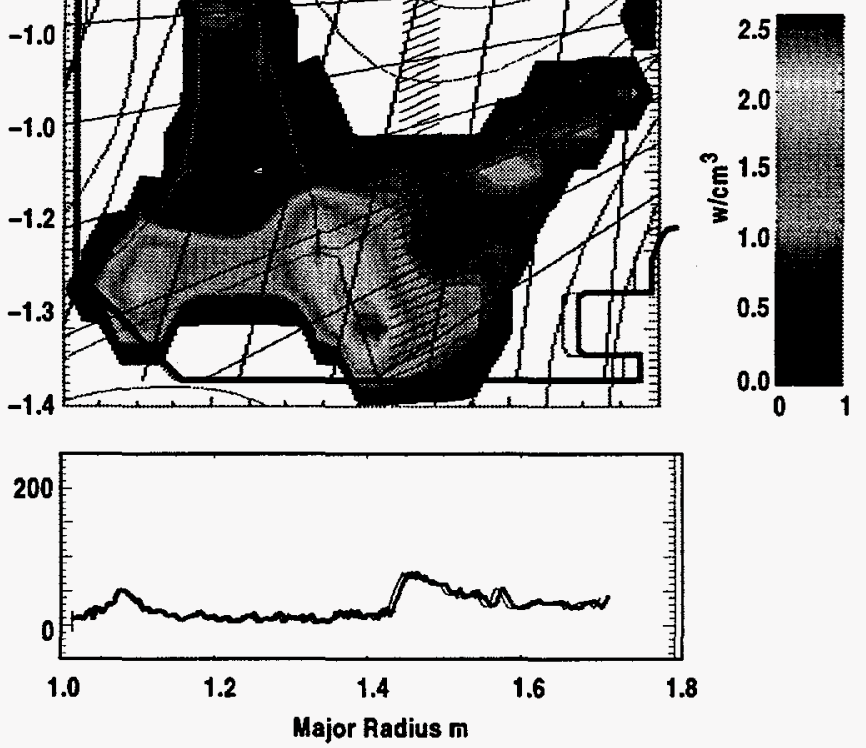

Fig. 2. Total radiated power profiles reconstructed from bolometer data for discharge 87638 (a) at $2037 \mathrm{~ms}$, before PDD operation, and (b) at $4310 \mathrm{~ms}$, during PDD operation. The cross hatched region is the divertor SPRED FOV and the nearly horizontal and vertical lines are the bolometer lines of sight. Also shown are the target plate heat flux profiles at these times showing a factor of 3 reduction at the OSP during PDD operation.

the overall peak bolometer signals near the OSP and the local peak near the ISP. SPRED data shows a large increase in DI and a decrease in CIV fractional power as the OSP moves through the view of the spectrometer, in agreement with the visible emission profiles. 

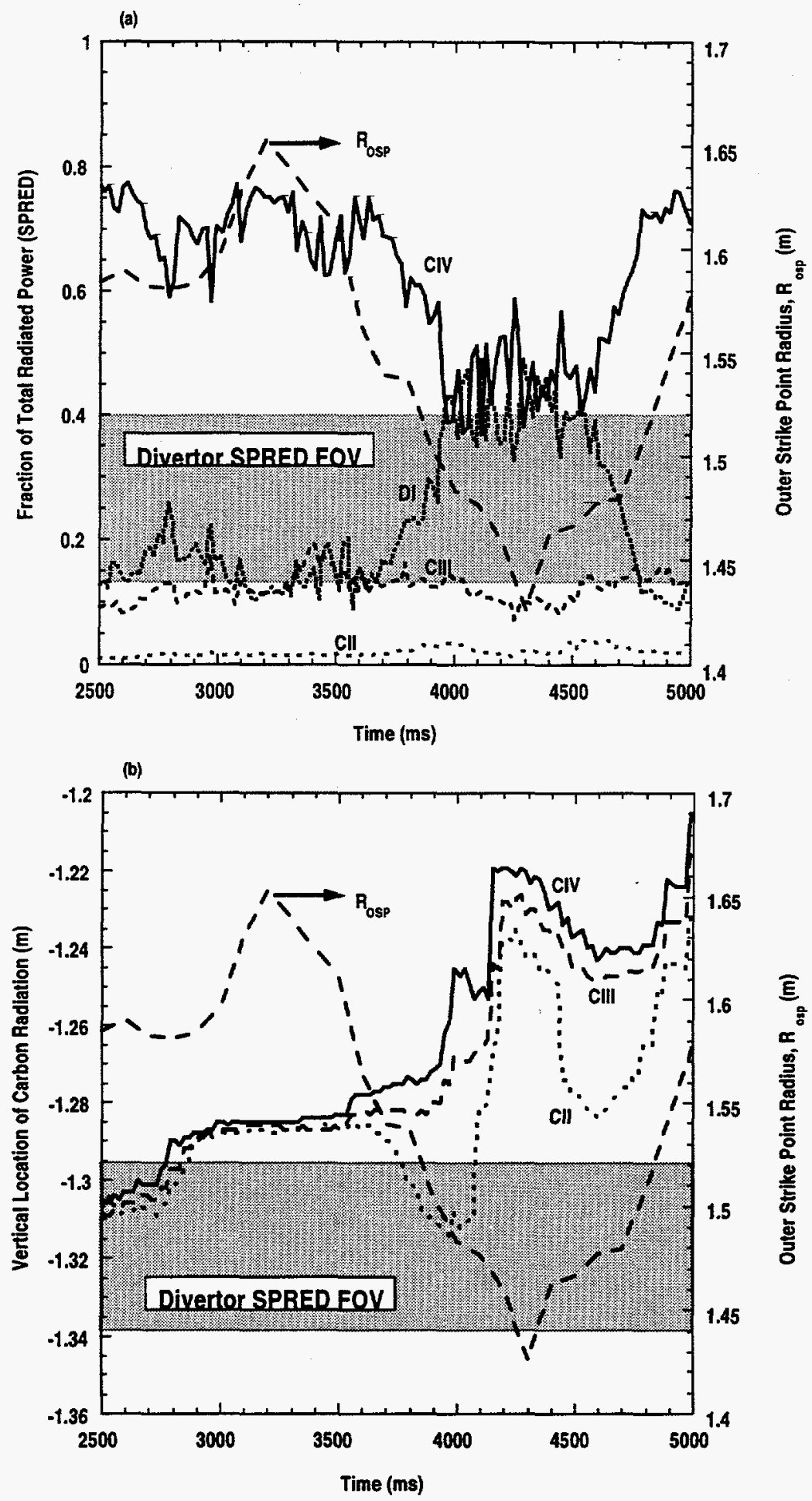

Fig. 3. Temporal evolution of EUV impurity emission from the divertor SPRED diagnostic and radial position of the OSP for discharge 87638. In (a) the fraction of the total radiated power inferred from the SPRED data is shown for DI, CII, CIII, and CIV emission. In (b) the inferred heights of the emission from CII, CIII and CIV are shown. 

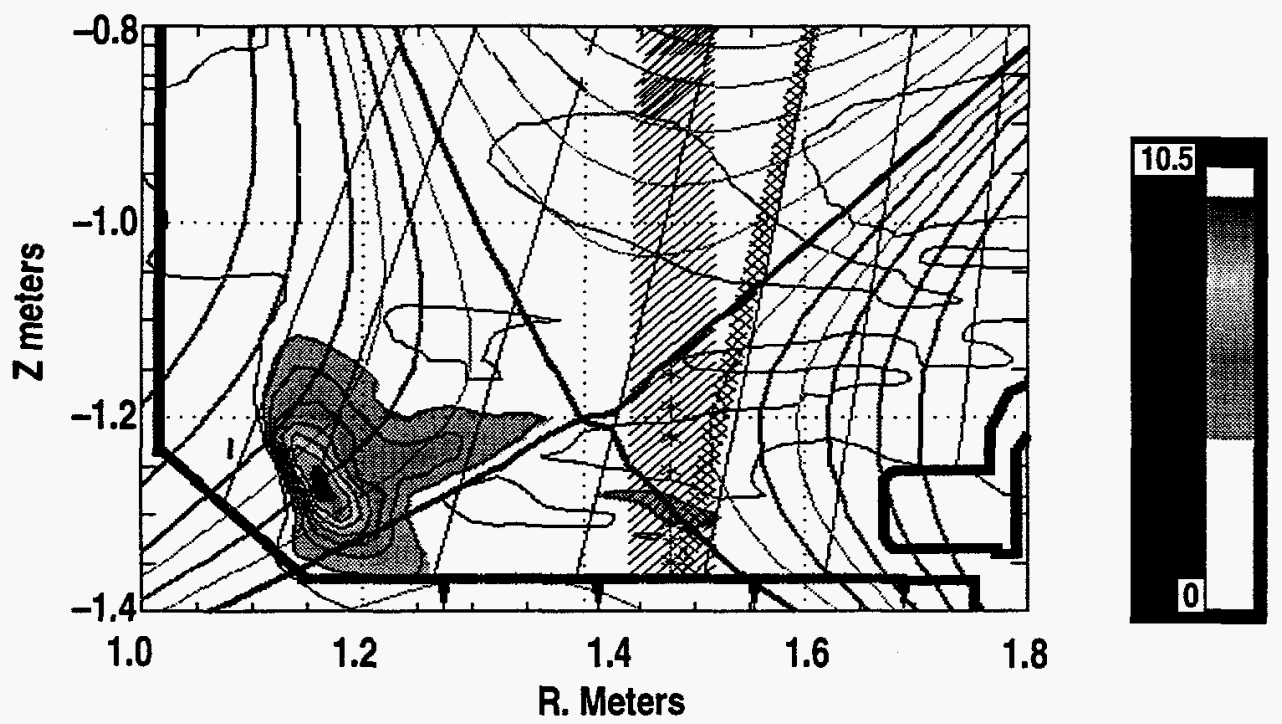

(a)
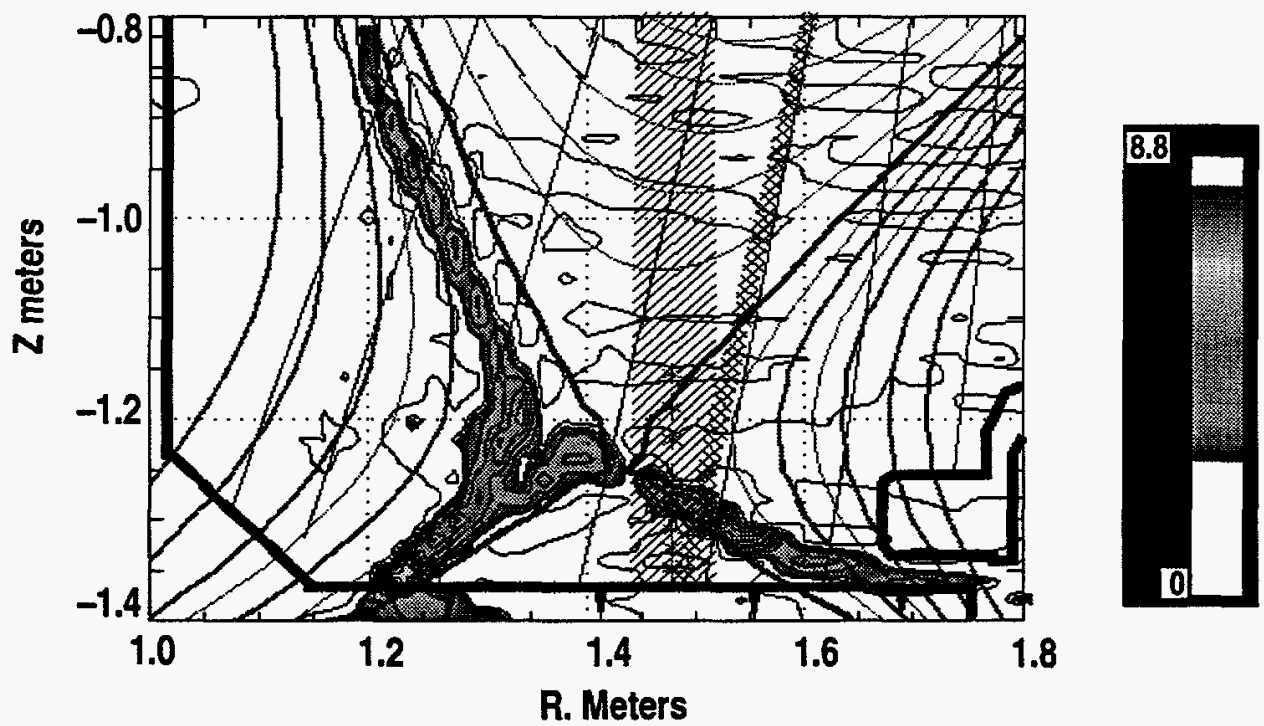

(b)

Fig. 4. Impurity visible line emission measured by the TTV during ELMing $\mathrm{H}$-mode prior to PDD operation for (a) $\mathrm{D}_{\alpha}(656.3 \mathrm{~nm}$, discharge 87164 at $1460 \mathrm{~ms})$ and (b) CIII $(464.7 \mathrm{~nm}$, discharge 87638 at $2040 \mathrm{~ms}$ ). Also shown are the divertor SPRED FOV (singly cross hatched), a divertor visible spectrometer FOV (doubly cross hatched) and the $\mathrm{D}_{\alpha}$ monitor lines of sight (nearly vertical lines). 

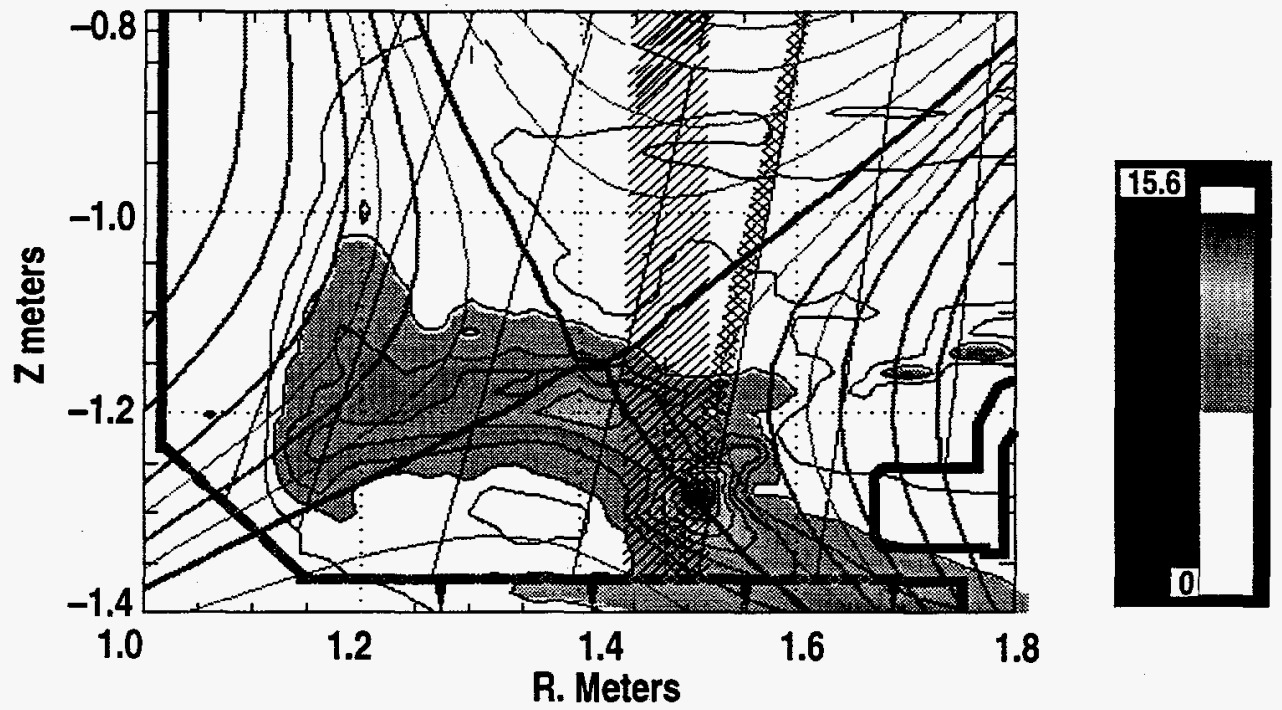

(a)
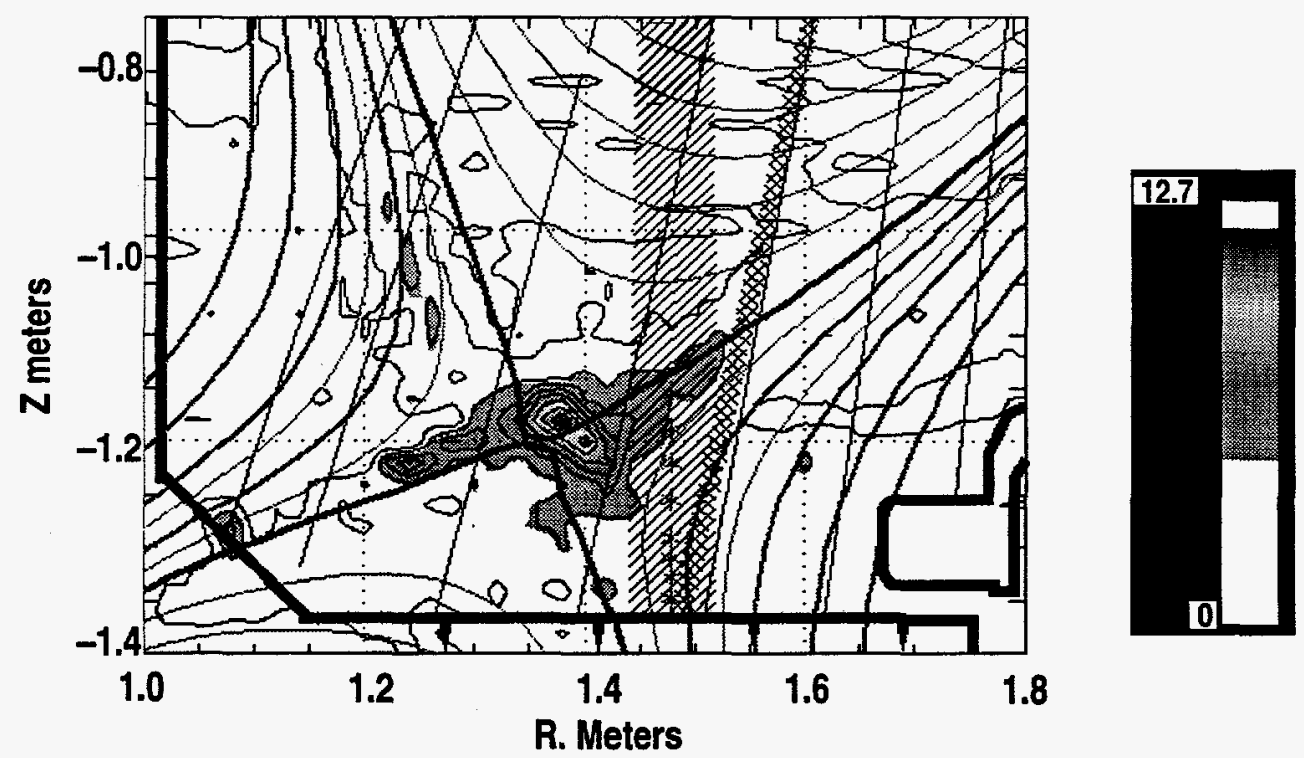

(b)

Fig. 5. Impurity visible line emission measured by the TTV during PDD operation for (a) $\mathrm{D}_{\alpha}(656.3 \mathrm{~nm}$, discharge 87164 at $3290 \mathrm{~ms}$ ) and (b) CIII (464.7 nm, discharge 87638 at $4310 \mathrm{~ms}$ ). 


\section{SOL AND DIVERTOR SIMULATION}

Simulations of the PDD conditions in these discharges are done with the UEDGE fluid plasma code [11]. The procedure for setting up UEDGE simulations of detached plasmas in DIII-D is given by Porter [12]. The profiles at the midplane were matched by UEDGE using $\mathrm{D}_{\perp}=0.2 \mathrm{~m}^{2} / \mathrm{s}, \chi_{\mathrm{e}}=\chi_{\mathrm{i}}=0.28 \mathrm{~m}^{2} / \mathrm{s}$, and target plate recycling coefficent, $\mathrm{R}=1.0$. A solution with thermally collapsed inner and outer divertor legs $\left(T_{e}=1-2 \mathrm{eV}\right)$ is obtained for the first time using the power flow measured in the experiments (Fig. 6). The poloidal extent to which the legs are collapsed is sensitive to the effectiveness of the outer and private flux pumping and to the impurity content in the simulations. Using outer wall albedo $=0.99(1 \%$ neutral pumping), private flux wall albedo $=0.98$ and $0.2 \%$ fixed carbon fraction of the electron density produced a solution with the $5 \mathrm{eV}$ contour $14 \mathrm{~cm}$ poloidally up from the target toward the X-point in the inner leg [Fig. 6(a)]. This contour is $6 \mathrm{~cm}$ off the target in the outer leg. The divertor Thomson data show it to be $10 \mathrm{~cm}$ from the outer target plate. Total recombination current was 3 times the target plate recycling current $(60 \mathrm{kA}$ compared with $20 \mathrm{kA}$ ) indicating that a significant neutral fueling source exists in the divertor leg plasma away from the target plates [Fig. 6(b)]. The Navier-Stokes treatment of momentum transfer from the plasma to the neutrals produces a gradual reduction of the parallel flow velocity in the SOL from a maximum $10 \mathrm{~cm}$ poloidally off the target to near zero at the target.

The DEGAS Monte Carlo neutrals transport code was used to simulate the detailed behavior of hydrogen atoms and molecules in the UEDGE plasma solution. Sources due to both recycling at the target plates and recombination within the thermally collapsed plasma were included. Results showed that the neutral source due to recombination was a significant contributor to the total pressure in regions with plasma temperature below $5 \mathrm{eV}$, accounting for $20 \%$ of the atomic pressure in these regions of both divertor legs. The simulated $D_{\alpha}$ emission integrated along the lines of sight of the experimental monitors was within a factor of 3 of the measurements throughout the divertor, and within $50 \%$ at the OSP. 


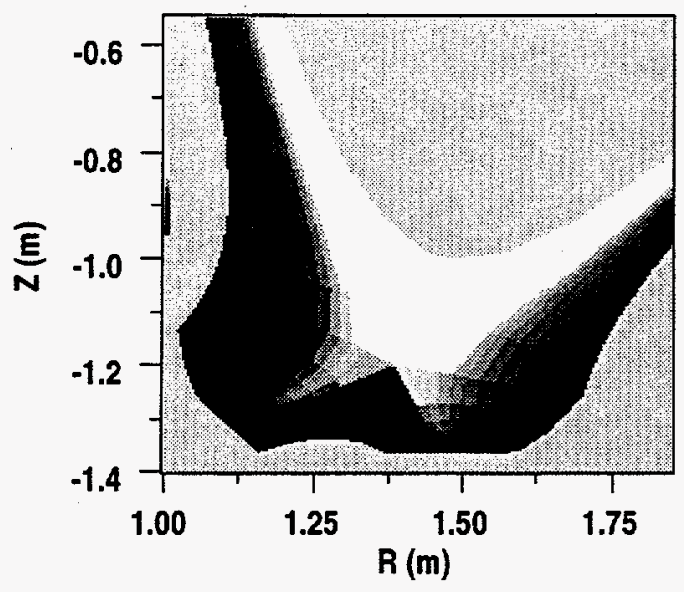

(a)
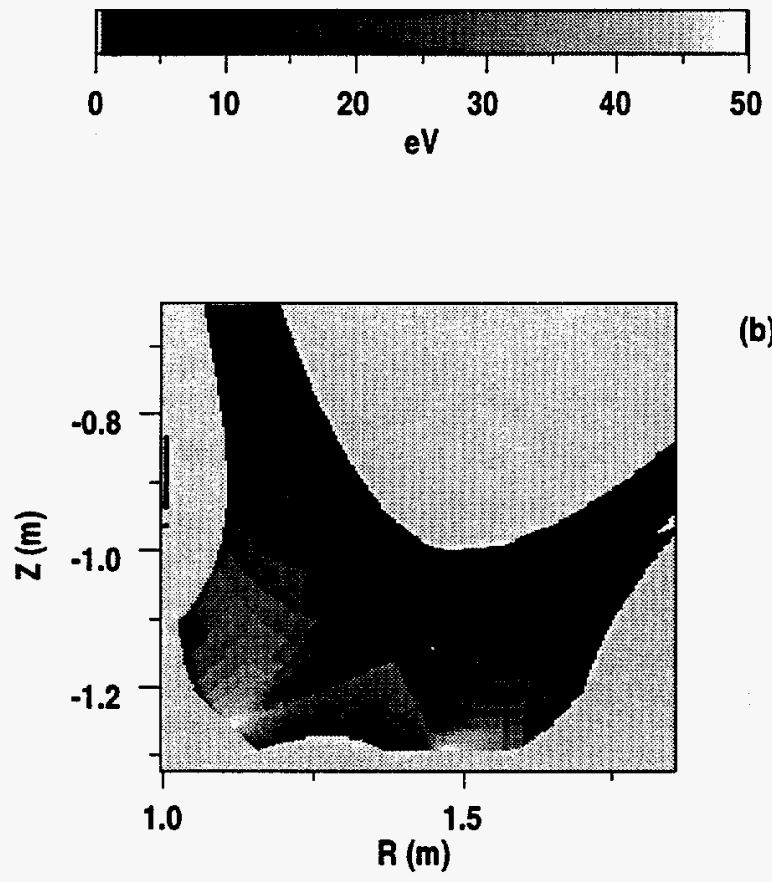

(b)

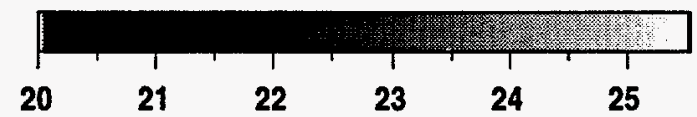

Fig. 6. Results from a UEDGE calculation for discharge 87506 at $3680 \mathrm{~ms}$ during PDD operation. In (a) the 2-D distribution of electron temperature is shown in which the plasma is thermally collapsed $(\mathrm{Te}<5 \mathrm{eV}$ ) approximately $14 \mathrm{~cm}$ poloidally from the ISP toward the X-point, and approximately $6 \mathrm{~cm}$ poloidally from the OSP. In (b) the resulting total recombination rate shows a large neutral source away from the strikepoints in both SOLs. 


\section{CONCLUSIONS}

Multiple divertor diagnostics measuring hydrogen and carbon impurity emission produce a consistent 2-D distribution of these radiating species in the DIII-D divertor. Comparison of that profile with the 2-D reconstruction of the total radiated power from the bolometer arrays shows that in ELMing $\mathrm{H}$-mode without deuterium injection the spatial distribution of hydrogenic radiation localized near the ISP corresponds to the radiated power profile there. During PDD operation with deuterium puffing, the radiated power profile shifts to the outer leg and $\mathrm{X}$-point regions. Hydrogenic radiation dominates near the OSP and carbon radiation (primarily CIV) dominates near the $\mathrm{X}$-point. This is in general agreement with previous observations on other tokamaks [4,5]. Estimates indicate that $\mathrm{L}_{\alpha}$ and CIV can account for as much as $90 \%$ of the radiated power in the highly radiating regions of the outer leg. Simulations of this PDD condition, obtained for the first time using the measured power flowing through the SOL and divertor, show thermal collapse of both divertor legs. The spatial distribution of the collapsed region is in good agreement with experiment. 


\section{REFERENCES}

[1] T. W. Petrie, et al., presented at 18th European Conference on Controlled Fusion and Plasma Physics, Berlin, 1991.

[2] T.W. Petrie, et al., "Divertor heat flux reduction by D2 injection in DIII-D," J. Nucl. Mat., 196-198, pp. 848, 1992.

[3] A.W. Leonard, et al., "Radiation Distributions in Detached Divertor Operation on DIII-D," presented at 22nd European Conference on Controlled Fusion and Plasma Physics, Bournemouth, UK, 1995.

[4] H. Kubo, et al., "Study of impurity and radiative losses in divertor plasmas with absolutely calibrated VUV spectrometers in JT60-U," Nucl. Fus., 33, pp. 1427, 1993.

[5] C. Kurz, et al., "Impurity sources at the first wall of Alcator C-Mod and their effect on the central plasma.," J. Nucl. Mat., 220-222, pp. 963, 1995.

[6] D.G. Nilson, et al., "Divertor Thomson Scattering on DIII-D," presented at Seventh International Toki Conference on Plasma Physics and Controlled Nuclear Fusion (ITC7), Toki City, Japan, 1995.

[7] S.L. Allen, et al., "First measurements of electron temperature and density with divertor Thomson scattering in radiative divertor discharges on DIII-D," J. Nucl. Mat., 1996.

[8] T.W. Petrie, "Investigation of electron parallel pressure balance in the scrape-off layer of deuterium-based divertor discharges in DIII-D," J. Nucl. Mat., 1996.

[9] J.G. Watkins, "Reciprocating and fixed probe measurements of $n_{e}$ and $T_{e}$ in the DIII-D divertor," J. Nucl. Mat., 1996.

[10] M.E. Fenstermacher, et al., "A tangentially viewing visible TV system for the DIII-D divertor," Rev. Sci. Inst., 1996.

[11] T.D. Rognlien, et al., "A fully implicit, time dependent 2-D fluid code for modeling tokamak edge plasmas," J. Nucl. Mat., 196-198, pp. 347, 1992.

[12] G.D. Porter, "Simulation of experimentally achieved detached plasmas using the UEDGE code," Physics of Plasmas, 1996. 


\section{ACKNOWLEDGMENT}

Work supported by U.S. Department of Energy under Contract Nos. DE-AC0389ER51114, W-7405-ENG-48, DE-AC04-94AL85000, DE-AC05-96OR22464, and Grant Nos. DE-FG03-86ER53266 and DE-FG03-95ER54294. 
